\title{
MIELOPATIAS: ASPECTOS DIAGNOSTICOS
}

\author{
A. SPINA-FRANCA * \\ P. N. B. SALUM** \\ J. C. P. LIMONGI** \\ A. BERGER ** \\ E. R. LOSBO **
}

Reavaliação dos conhecimentos sobre aspectos fisiopatológicos do acometimento da medula espinhal vem sendo motivada pelos resultados de observações clínicas e farmacológicas no decurso dos cuidados dispensados a pacientes com mielopatias de etiologia diversa $\mathbf{7 , 8 , 1 4 , 1 5}$. Igualmente, a reavaliação resulta dos novos conhecimentos sobre neuroimunologia, frente aos quais a importância da necrose, da desmielinização e da inflamação vem sendo reanalisada experimentalmente e no homem $\mathbf{1 , 4 , 6}$.

Para empreender análises dirigidas a esses novos aspectos impõe-se avaliar a caracterização diagnóstica. Dado ser essencialmente clínica a constatação da vigência de mielopatia, torna-se necessário caracterizar o diagnóstico etiológico e, secundariamente, os processos fisiopatológicos envolvidos no acometimento da medula espinhal.

Dentro desse propósito foram avaliados os critérios diagnósticos adotadas para mielopatias e estabelecidos através da sedimentação da experiência clínica em um mesmo Serviço de Neurologia e no transcorrer de duas décadas.

\section{CASUISTICA E METODOS}

Foram analisados os dados sobre 353 pacientes com mielopatias internados nu decurso de 20 anos (1959-1978) na Divisăo de Neurologia do Hospital das Clínicas da Faculdade de Medicina da Universidade de Săo Paulo. Os critérios adotados para a seleção dos casos foram os seguintes: pacientes nos quais havia sintomas e sinais próprios a acometimento medular; esse acometimento medular representava o aspecto capital da doença por eles apresentada; o acometimento medular năo era devido a traumatismo ou a tumor; tal acometimento năo constituía aspecto do acometimento sistematizado de vias sensitivas ou motoras, como se observa em certas afeçбes degenerativas do sistema nervoso.

Dos 353 pacientes, 222 eram do sexo masculino e 131, do feminino; 272 eram brancos, 79 pretos ou pardos e 2, amarelos. Distribufam-se quanto a idade entre

Trabalho do Centro de Investigaçōes em Neurologia do Departamento de Neuropsiquiatria da Faculdade de Medicina da Universidade de Săo Paulo: * Professor adjunto; * Médico adido. Apresentado no V Congresso Pan-Americano de Neurologia (Caracas, 1979). 
3 meses e 88 anos: até 10 anos, 33 pacientes; de 11 a 20 anos, 62; de 21 a 30 anos, 66; de 31 a 40 anos, 72; de 41 a 50 anos, 61; de 51 a 60 anos, 38 e acima de 60 anos, 21. Provinham de outros paises 8 pacientes e os demais, do Brasil: do norte, 3; do nordeste, 40; do oeste, 11; do sul 20 e do sudeste (região em que está situado o hospital) 271.

Foram avaliadios em cada caso: o tempo de doença por ocasiăo da internaçăo; o moto de apresentação do processo (agudo, sub-agudo, crónico, em surtos); o quadro clínico e a respectiva forma de evolução; a concomitancia a processos mórbidos sistêmicos e a relaçăo a condições iatrógenas; a resultados de exames paraclínicos gerais e do liquido cefalorraqueano (LCR); resultados de exames morfológicos (biópsia ou necrópsia).

\section{RESULTADOS}

Os casos foram distribuidos conforme a mielopatia estivesse relacionada a: siringomielia (5 cas08): comprometimento vascular (15 cas08); vigência e processos carenciais, como a deficiência de cianocobalamina, (67 casos); processos inflamatórios devidos a infeç̧os ou infestações (82 ca808); processos nos quais fatores autoimunes alcançam relevo (51 casos); processos nos quais o acometimento medular foi de natureza primária, representou o aspecto capital do acometimento do sistema nervoso e era passivel de ser relacionado ao grupo anterior (133 casos).

\section{COMENTARIOS}

Surincomiblia - O diagnóstico de siringomielia fol baseado nos 5 casos em dados essencialmente clínicos. Estes foram comprovados morfologicamente em dois pacientes: a necrópsia em um e à cirurgia em outro. A idade de início da sintomatologia distribufa-se entre 11 e 30 anos.

Compdomitimento da Vagcularizagão Mmular - A maior concentração de casos (6 dos 15 estudados) encontrava-se situada na faixa etária de 11 a 20 anos. A distribuição topográfica da sindrome, aliada ao modo de instalação do processo (agudo, ictal) representaram o ponto essencial para o diagnóstico clínico de mielopatia devida a insuficiencia vascular. $\operatorname{Em} 9$ pacientes a sindrome era compativel a comprometimento no território da artéria radicular magna: em um destes pacientes foi constatada cirurgicamente a existencia de malformação arteriovenosa intrarraqueana lombar. Em três pacientes a síndrome tínha topografia cervical; só em dois destes a instalação do processo foi de tipo crónico, evoluindo progressivamente. Fm ambos a necrópsia demonstrou a vigencia de mielopatia vascular progressiva.

Mtraopatias Carrenciajs - Raquitismo ou pelagra ou carências múltiplas foram relacionadas ao estabelecimento de mielopatia em 4 casos. Neles a correção das avitominoses levou a remissão parcial ou completa do processo. 
Em 63 pacientes fol estabelecido o diagnóstico de neuropatia por carencia de cianocobalamina segundo os critérios adotados em nosso meio 12 . A doença se estabeleceu de modo sub-agudo em 4 e de modo mals lento nos restantes. $O$ componente medular do processo foi reconhecido clinicamente em porçoes inferiores de medula com mais frequência (cérvico-torácico em 25; tóraco-lombar em 38). O diagnóstico baseou-se no quadro clínico em 5 pacientes e em dados de necrópsia em 2. Nos demais, na vigência quer de déficit na absorçăo de clanocobalamina radioativa (49 casos), quer de hipo ou acloridria gástrica (36 casos), acompanhada de gastrite crónica atrófica constatada mediante biópsia. de salientar que 24 destes pacientes eram etilistas crónicos declarados e que 7 foram previamente submetidos a gastrectomia. 0 quadro clínico se estabeleceu entre 31 e 60 anos de idade em 52 dos 63 casos.

Mmajopatias In bacciosas - Poliomielite anterior aguda, abscesso bacteriano, sifilis, tuberculose, paracoccidioidomicose, ameblase primária, toxoplasmose, cisticercose e esquistossomose compóem o elenco diagnóstico neste grupo mórbido ( 82 casos).

o diagnóstico de poliomielite anterior aguda baseou-se essencialmente em dados clínicos. Em um dos pacientes fol comprovado ser devida a poliovírus tipo 2; nos demais o estudo virológico năo fol efetuado ou fol inconclusivo. Houve nitida predominancia da faixa etária de até 10 anos sobre as demals (6 dos 9 casos).

Abscesso epidural por estafilococo e abscesso subdural por estreptococo levaram a comprometimento medular agudo, secundário, em dois casos, ambos de evoluçăo fatal e nos quais houve comprovaça morfológica.

A vigência de paracoccidioidomicose sistêmica serviu de elemento ao diagnóstico etiológico de mielopatía observada em um paciente cujo LCR apresentava alteraços inflamatórias de tipo crónico. A sindrome liquórica da neurocisticercose permitiu $o$ estabelecimento do diagnóstico em caso de mielopatia torácica $\left(T_{7}\right)$. A vigencia de toxoplasmose sistemica, acompanhada de coriorretinite e calcificaços patológicas intracranianas, levou ao diagnóstico de mielite por toxoplasma (nivel lombar) em paciente cujo LCR apresentava alteraçós inflamatórias de típo crónico. A constataçáo de ameba Naegleria sp. no LCR levou ao diagnóstico etiológico em paciente cujo estudo Já fol registrado 11 .

Os 19 casos nos quais a mielopatia foi relacionada a tuberculose constituem o único agrupamento de pacientes em que o contingente de pardos ou pretos fol conspicuo (10 casos). Neste agrupamento predominou a instalaçăo do processo entre 20 e 50 anos de idade (14 casos). O comprometimento medular decorria de mal de Patt em 12 pacientes. Nos restantes havia mieloaracnoidite ou meningomielite. Nestes, o conjunto de alteraçóes do LCR fol o principal elemento diagnóstico, associadio a constataçăo da doença em outros órgãos, em especial nos pulmóes 9.

Mielopatia em infestaça por ovos de schistosoma mansoni (20 casos) fol verificada em especial em pacientes oriundos de zonas nas quais a esquistossomose é endémica, predominando naqueles vindos do nordeste do Brasil. Na maioria (15 casos) a idade do inficio da doença distribuía-se entre 20 e 40 anos. A instalaça aguda ou sub-aguda da sintomatologla foi a mals comum (15 casos), com apreseritacăo transversa, em nivel torácico, predominantemente (17 cas.os). Ao conjunto das alteraçóes do LCR associava-se: vigência de infestaçăo sistêmica em 15; positividade de reaçres imuno- 
lógicas para esquistossomose no LCR em 3; demonstração morfológica de infestação mielorradicular em 2. Esta altima năo tem sido registrada comumente 10. Detalhes sobre alguns casos foram registrados anteriormente 13.

Fol imputada à sifilis a etiologia do processo em 28 casos. A tabes dorsalis (10 casos) e a paraplegia de Erb (2 casos) representam contingente importante no grupo. Diversas formas de acometimento luético meningovascular, todos de nivel torácico ou lombar, ocorreram nos outros 16 casos. Fm 7 destes havia positividade de reaç⿸es imunológicas para sffilis no LCR; em todos, estas foram positivas no soro. Só em 3 casos deste grupo a doença se iniciou antes de 40 anos de idade e só em 3 , de modo agudo ou sub-agudo.

mutapatias retacionadas a Fatorieg autolmunes - Săo abrangidos neste grupo processos que evoluiram de modo monofásico (mielopatias pós-vacinação, pós-infecciosas e pós-intoxicaçăo) ou polifásico (esclerose multipla e neuromielite óptica).

As mielopatias pos-vacinacáo, pós-infecciosas e pós-intoxicasao foram caracterizadas por referência a vacinaçăo (16 casos), infeç̧ăo (13 casos) ou, em dois casos, intoxicaçăo (sulfeto de carbono em um paciente; composto organofosforado em outro) precedendo a instalaçåo do processo. Excetuando os pacientes com mielopatía pós-intoxicaçăo, os demais apresentavam idade entre 10 e 30 anos. Fm todos, o processo se instalou de modo agudo ou sub-agudo. A apresentaçăo transversa do quadro predominou sobre a ascendente, da mesma forma que a topografia torácica (16 casos), embora fosse importante o contingente no qual esta era cervical (9 casos). Só em dois casos a evoluçáo da doença fol fatal. Em ambos a mielopatia se instalou após vacinaçáo anti-rábica; só um deles foi submetido a necrópsia, sendo constatada mielopatía cervicotorácica, havendo degeneraçăo cordonal anterior, lateral e posterior.

Nos casos de mielopatía pós-vacinaçáo a doença estabeleceu-se após vacina contra raiva (12 casos), contra variola (3 casos) e contra febre amarela (1 caso). Relato anterior abrange parte dos pacientes com mielopatia pós-vacinaçăo anti-rábica 1. Na maioria dos 12 casos de mielopatia pós-vacinação anti-rábica, o quadro se instalou entre a administraçăo da décima e da décima terceira dose de vacina; cerca de 4 semanas nos 3 casos de mielopatía após a vacinaçăo antívarílica; 5 días após, para o de vacinaçáo contra febre amarela.

Săo semelhantes quanto à apresentação e evoluçăo os dados quanto a mielopatias pós-infecciosas, as quais se instalaram entre 1 e 3 semanas depois de processo infeccivso inespecifico, muitas vezes caracterizado como de tipo gripal e, num deles, como gastrointegtinal.

Nos 2 casos de mielopatia pós-intoxicaçăo, o quadro se instalou durante a terceira simana após o acidente e após terem cessado as manifestaçరés gerais.

A esclerose múltipla (8 pacientes) e neuromielite óptica (12 pacientes) compreendem - segundo agrupamento deste item. Os pacientes com neuromielite óptica foram estudados, na maioria, entre 11 e 30 anos de idade (8 casos); em dois a coença se manifestou mais precocemente (4 e 5 anos de idade respectivamente). Os casos de esclerose multipla foram estudados entre 20 e 40 anos de idade. Para ambos os grupos predominou a apresentaçăo torácica (10 casos). 
Em todos os pacientes com esclerose múltipla o diagnóstico baseou-se fundamentalmente na ocorrência de surtos de ataques e remissåo da doença, sendo estudadcs por ocasiăo do terceiro ou do quarto surto.

Nos pacientes com neuromielite óptica o diagnóstico clínico foi complementado pelos dados de necrópsia em 2: em um havia necrose medular cervico-torácica que se acompanhava de infiltrado imunocompetente perivascular que se estendia cranialmente até a medula oblonga e se acompanhava de destruiçăo do quiasma óptico; em outro foi encontrada desmielinizaçăo medular (em nível torácico) e dos nervos ópticos. A evolução em surtos foi constatada em 5, sendo estudados por ocasiăo do sétímo em um e do terceiro ou quarto em 4.

Mumitas Primárias - Săo abrangidos neste grupo 133 pacientes: 16 com mieloaracnoidite primária e 117 com mielites primárias.

Nåo houve entre os 16 pacientes com mieloaracnoidite primdria um predominio de determinada faixa etária sobre as demais. Os achados neurorradiológicos serviram de base ao estabelecimento do diagnóstico de mieloaracnoidite em 15 casos deste grupo; em 1, foi ele estabelecido à círurgia. Predominou a apresentaçăo transversa e em nível torácico (10 casos); quanto ao modo de apresentaçáo predominou o agudo e sub-agudo (11 casos)

Os 117 pacientes com mielites primarias foram subdivididos de acordo com o modo de instalação da mielopatia: agudo (46 casos), sub-agudo (13 casos), crônico (58 casos).

Em sua maioria, as mielopatias primárias de estabelecimento agudo (até dentro de uma semana) ou sub-agudo (de 1 a 4 semanas) estabeleceram-se até a idade de 30 anos (45 casos), tendo predominado entre elas a apresentaçăo transversa em nivel torácico (37 casos). O mesmo tipo de apresentaçăo (37 casos) predominou naquelas de estabelecimento considerado crônico, embora a faixa etária em que ocorreu mais comumente foi a de 20 a 50 anos de ilade (38 casos).

O diagnóstico clínico foi complementado pelos dados de necrópsia em 5 dos 6 pacientes que faleceram (4 com formas agudas; 1 com forma crônica). Desde a mielite necrotisante agưa até a mielopatia desmielinisante foram encontradas (esta no caso de forma crônica). Focos de amolecimento múltiplos, desmielinização multifocal e infiltrado inflamatório imunocompetente foram também registrados.

Nenhum vínculo a outros processos mórbidos em atividade puderam ser estabelecidos para todos os casos deste grupo, como em outros estudos efetuados em nosso meio 3,5.

\section{CONCLUSOES}

A análise da casuistica revista permite salientar alguns aspectos quanto à fisiopatologia do acometimento medular.

Primeiramente, destacam-se fatores anatômicos, particularmente relacionados à irrigação medular. Desempenham eles papel importante no desencadeamento de mielopatias, especialmente quando considerada a forma transversa e o nível torácico. Este foi o mais frequentemente observado na casuistica analisada. 
Em segundo lugar salienta-se a desmielinização - primária ou secundária - resultante de um só episódio, de vários episódios, ou continuada.

$O$ terceiro aspecto a destacar é o da vigência de reação inflamatória, quer como expressão de resposta a infecção ou a infestação, quer como expressão de fenômenos autoimunes. A mielomalácia e a necrose medular podem ser lembradas ainda.

Todavia, torna-se difícil estabelecer um vínculo fisiopatológico entre os fatores apontados levando-se em conta apenas os aspectos clínicos ou, então, os morfológicos oriundos de estudo necroscópico, dado o pequeno número de pacientes que vêm a falecer durante o período de observação.

É necessário, parả considerar esse vinculo, estudar informes relacionados a imunobiologia do processo. Nesse particular destacam-se os dados obtidos mediante o estudo do dual citoproteico do LCR.

\section{RESUMO}

E feita reavaliação dos aspectos que levaram ao diagnóstico etiológico em 353 pacientes com mielopatia não-traumática e não-tumoral observados no decurso de 20 anos: siringomielia, 5 casos; vascular, 15 casos; carencial, 67 casos; infecciosa ou por infestação, 82 casos; pós-vacinação, pós-infecção ou pós-intoxicação, 31 casos; esclerose múltipla e neuromielite óptica, 20 casos; primária, 133 casos.

Em função do diagnóstico são analisados os aspectos que podem contribuir aos conhecimentos sobre os mecanismos fisiopatológicos interessados na deflagração do acometimento medular noo que tange às alterações imunobiológicas. Nesse sentido é considerado o papel da necrose, da desmielinização e da inflamação e o respectivo interrelacionamento.

\section{SUMMARY}

\section{Myelopathies: diagnostic aspects}

A re-evaluation is made of those aspects which led to the etiologic diagnosis in 353 patients who suffered from non-traumatic, non-tumoral myelopathies, and whose cases were studied along a period of 20 years. The cases were distributed as follows: syringomyelia, 5 cases; vascular myelopathy, 15 cases; privation caused myelopathies, 67 cases; infectious or infestation caused myelopathies, 82 cases; post-vaccination, post-infection or post-intoxication, 31 cases; multiple sclerosis and optic neuromyelitis, 20 cases; primary myeolopathy, 133 cases.

With basis on the diagnosis, those aspects which may contribute to the existing knowledge about physiopathologic mechanisms related to the onset of spinal cord involvement, as related to immunobiologic alterations, are analysed. The role of necrosis, demyelinization and inflammation, and their respective interrelashionships are considered in this light. 


\section{REFERENCIAS}

1. ALLWhRETTI, N. \& MARUSIC, M. - Experimental allergic encephalomyelitis in T-lymphocyte deticient rats. Experientia 32:109, 1970.

2. ASSIS, J. L. - Neurological complication of antirabies vaccination in São Paulo, Brazil: clinical and therapeutical uspects. J. neurol. Sci. $26: 593,1975$.

3. CODECEIRA Jr., A. \& TRAVASSOS, F. - Meningomielite eosinofilica. Neurobiol. (Recife) $35: 203,1972$.

4. CONNOLLY, J. H.; HUTChInSON, W. M.; ALIJH, I. V.; LYTTLE, J. A.; SWALLOW, M. W.; DERMOTT, E. \& TROMSON, D. - Carotid artery thrombosis, encephalitis, myelitis and optic neuritis associated with rubella virus infections. Brain 98:583, 1975.

5. FACURE, N. O. \& SPINA-FRANÇA, A. - Meningorradiculomielites provavelmente a virus: aspectos da incidência em nosso melo. Arq. Neuro-Psiquiat. (Såo Paulo) $24: 264,1966$.

6. HALLIDAY, A. M. \& MCDONALD, W. I. - Pathophysiology of demyelination disease. British med. Bull. 33:21, 1977.

7. HALSTEAD, L. S.; CLAUS-WALKER, J. \& HRNA, D. - Neurologically active druga in spinal cord injury: a clinical coding system. Arch. phys. Med. Rehabil. 50:358, 1978.

8. HOWELL, D. A. - Radiation myelopathy. Develop. Med. Child. Neurol. 21:653, 1979.

9. JOHN Jr., J. F. \& DOUGLAS Jr., R. G. Tuberculous arachnolditis J. Pediat. $86: 235,1975$.

10. QUEIROZ, L. S.; NUCCI, A.; FACURE, N. O. \& FACURE, J. J. - Massive spinal cord necrosis in schistosomiasis. Arch. Neurol. (Chicago) 36:517, 1979.

11. SALles-gOMES Jr., C. E.; BARBOSA, E. R.; NOBREGA, J. P. S.; SCAFF, M. \& SPINA-FRANÇA, A. - Meningoencefalomielite amebiana primária. Arq. NeuroPsiquiat. (Sฐ̃o Paulo) 36:139, 1978.

12. SCAFF, M. - Contribuiçăo para o estudo da neuropatia por deficiéncia de vitamina B-12. Tese. Faculdade de Medicina, Universidade de Sáo Paulo. São Paulo, 1971.

13. SCAFF, M.; RIVA, D. \& SPINA-FRANÇA, A. - Meningorradiculomielopatia esquistossomótica. Arq. Neuro-Psiquiat. (São Paulo) 29:227. 1971.

14. SLAGER, U. T. - Diabetic myelopathy. Arch. Pathol. Lab. Med. 102:467, 1978.

15. YOUNG, J. S. - Collaborative research in spinal cord injury. Orthop. Clin. North Amer. 9:277, 1978.

Ceniro de Investigaçōes cm Neurologia - Caixa Postal 5199 - 01600 sáo Paulo, 8P - Brasil. 